\title{
FEATURE
}

\section{Soil ecosystem services and intensified cropping systems}

Kenneth R. Olson, Mahdi Al-Kaisi, Rattan Lal, and Lois Wright Morton

E fforts to meet the food and energy needs of an expanding world population have led to a large-scale expansion and intensification of crop production systems. A major challenge of the twenty-first century is ensuring an adequate and reliable flow of essential ecosystem services (Biggs et al. 2012; Hatfield and Walthall 2015) as cropping systems are intensified. Ecosystem services are the provisioning, regulating, supporting, and cultural functions that soil, water, vegetation, and other natural resources provide (MEA 2005). The conversion of natural ecosystems to cultivated cropland has eroded the capacity to efficiently retain and sequester soil organic carbon (SOC) (Olson et al. 2012), an essential ecosystem service of soil, and created a paradox in our attempts to achieve sustainable agricultural intensification, ecosystem resilience, and human food security (Biggs et al. 2012).

SOC stocks are critical to the provisioning and regulating services (figure 1) that underlie the production of food, fresh water, air quality, erosion prevention, nutrient cycling, and support of habitat (Dominati et al. 2010; Adhikari and Hartemink 2016). The health of soil, its properties, formation and distribution, processes, and interactions with water, organisms and plants influence the numerous functions and roles it serves (Adhikari and Hartemink 2016). Further, how humans value the functions of soil affects how soil is managed and its capacity to deliver the variety of ecosystem services needed to assure a sustainable

Kenneth R. Olson is professor emeritus of the Department of Natural Resources and Environmental Sciences, College of Agricultural, Consumer, and Environmental Sciences, University of Illinois, Urbana, Illinois. Mahdi AtKaisi is a professor of agronomy, Department of Agronomy, College of Agriculture, lowa State University, Ames, lowa. Rattan Lal is a professor in the School of Environment and Natural Resources, The Ohio State University, Columbus, Ohio. Lois Wright Morton is a professor of sociology, College of Agriculture, lowa State University, Ames, lowa.

\section{Figure 1}

Agroecosystem services provided by soil organic carbon (SOC) in corn-based cropping systems of agriculture (adapted from Adhikari and Hartemink [2016], table 2).

\section{Provisioning services \\ - Food and fuel \\ - Raw materials \\ - Fresh water/water retention, purification \\ Regulating services \\ - Climate and greenhouse gas regulation \\ - Water regulation \\ - Erosion and flood control \\ - Pest and disease regulation \\ - Carbon sequestration \\ - Water purification by denaturing of pollutants}

\section{Cultural services}

- Recreational/ecotourism

- Aesthetic/sense of place

- Knowledge/education/inspiration

- Cultural heritage

- Therapeutical

\section{Supporting services}

- Weathering/soil formation

- Nutrient cycling

- Provisioning of habitat

environment (Hatfield and Morton 2013). Human activities and natural processes have spatial and temporal effects on the capacities of SOC stocks to provide a flow of services. Soil degradation processes in intensified cropping systems affect SOC stocks and are one of the most dramatic examples of ecosystem deterioration (Swinton et al. 2007; Dominati et al. 2010) limiting agricultural productivity and ecosystem health. Ecosystems and human well-being are interdependent; thus, understanding the role of SOC as a factor in the quality and type of ecosystem services produced in intensified production systems is central to developing effective management strategies that guard against SOC stock depletion.

Cropping systems that are dominated by a single annual crop, such as corn (Zea mays L.), are considered corn-based, while dual cropping systems, such as cornsoybean (Glycine max [L.] Merr.), are considered corn-soybean based. There is a great deal of variation in crop rotations and management practices among corn-based and corn-soybean based systems. And it is these variations, such as type of tillage system, drainage systems, use of cover crops, construction of grass waterways and buffers, and terraces, which influence whether SOC is retained, enhanced, and potentially sequestered or is simply lost, resulting in ecosystem degradation. The depletion of SOC as a result of soil degradation within intensified agricultural systems can lead to loss of nutrients and soil structure, loss of soil resilience, a loss of soil biodiversity, and disruption to key biotic and abiotic processes necessary for productivity (Lal 2015). The intent of this paper is to examine the interdependence of soil ecosystem services, SOC stocks, and human management.

\section{ECOSYSTEM SERVICES OF SOIL ORGANIC CARBON STOCKS}

Soil plays a number of roles in providing ecosystem services associated with production systems: fertility, filter and reservoir, 
structure, climate regulation, biodiversity conservation, and resource use (table 1) (Dominati et al. 2010). Two dominant forms of carbon (C) contained in soil are organic carbon (OC) and inorganic carbon (IC), and in humid regions most of the $\mathrm{C}$ is held as SOC (with the exception of calcareous soils). The term SOC refers to the $\mathrm{C}$ that occurs in the soil organic matter (SOM) within the soil, and SOC comprises roughly $58 \%$ of SOM (historic estimate that was recently questioned [Hussain and Olson 2000]). The SOC is most highly concentrated in the top $20 \mathrm{~cm}$ (8 in) and decreases with soil depth down to approximately $85 \mathrm{~cm}$ (33.5 in). Thus, SOC contained within the top soil layer is more likely to be affected by cultivation and management practices than deeper in the rooting zone.

The SOM, a key property of soil, consists of previously living plant and animal residues in different stages of decomposition. The SOM is a reservoir for essential nutrients needed for plant growth and development, such as nitrogen $(\mathrm{N})$, phosphorus $(\mathrm{P})$, sulfur $(\mathrm{S})$, and micronutrients, and is one of the major binding agents of soil aggregation. It holds particles together and creates soil pores within and between aggregates to provide air and moisture to the roots and drain excess water (Al-Kaisi et al. 2014). SOC is the main source of food for soil microorganisms. Soil aggregates can be disrupted by tillage thereby increasing the availability of $\mathrm{C}$ to microorganisms, which can result in release of carbon dioxide $\left(\mathrm{CO}_{2}\right)$ back to the atmosphere. In addition to aggregation characteristics, soil color is an indication of high or low SOC content. Darker soil has a higher SOC content than lighter colored soil. Increasing the level of SOM can increase a soil's water holding capacity and make crops less susceptible to drought (Al-Kaisi et al. 2014).

The agroecosystem services that SOC stocks offer to annual cropping systems, such as corn-based or corn-soybean based systems, are quite similar to other types of ecosystems as delineated by the Millennium Ecosystem Assessment (MEA 2005): provisioning, regulating, cultural, and supporting ecosystem services (figure 1) (Adhikari and Hartemink 2016). Some ecosystem ser-

\section{Table 1}

Roles of soil in the provision of ecosystem services (adapted from Dominati et al. [2010]).

\begin{tabular}{ll}
\hline Role & Description of ecosystem service \\
\hline Soil fertility & $\begin{array}{l}\text { Plant growth is enabled by soil nutrient cycles that ensure fertility } \\
\text { renewal and deliver nutrients to plants. } \\
\text { Filter and reservoir }\end{array}$ \\
$\begin{array}{l}\text { Water is purified when soils fix and store solutes passing through } \\
\text { micro- and macroaggregates. Soil also cycles and stores water for } \\
\text { plant use and mitigates flooding. } \\
\text { Soil provides physical support to plants for root development } \\
\text { and anchoring. } \\
\text { Structural }\end{array}$ & $\begin{array}{l}\text { Climate regulation can occur through soil carbon sequestration and } \\
\text { regulation of greenhouse gas (nitrous oxide and methane) emissions. }\end{array}$ \\
Climate regulation & $\begin{array}{l}\text { Soil provides habitat for biodiversity, including diverse biological species } \\
\text { and activities that affect soil structure, nutrient cycling, and detoxification. }\end{array}$ \\
Biodiversity conservation & Soil can be a source of materials like peat and clay. \\
Resource & Soil microbes are sources of antibiotics. \\
Pharmaceutical & Soil is an archive of human and planetary history. \\
Archival & Soil is an inspiration to art and culture with spiritual values. \\
Cultural &
\end{tabular}

vices enhanced by SOC stocks are critical to achieving more sustainable production, management, and land use. Of particular concern are the climate and greenhouse gas (GHG) regulating services that SOC offers under increasingly variable short- and longterm weather patterns, which are affected by and in turn affect SOC stocks. The preservation of $\mathrm{SOC}$ is through $\mathrm{C}$ sequestration processes that include the removal and storage of $\mathrm{CO}_{2}$ from the atmosphere through photosynthesis and storage in soil as SOM. These processes provide ecosystem services by increasing SOC stock in the soil reservoir pools rather than in the atmosphere. The monitoring of SOC stock over time is a challenge, and SOC stock protocols that quantify the anthropic impact as a result of management and land use changes must include baseline measurements to measure change over time (Olson 2013). Other SOC regulating services are water regulation through improvement of water movement in soil, increased storage in soil, and improvement of biodiversity and nutrient recycling.

\section{SOIL DEGRADATION AND GREENHOUSE GAS EMISSIONS}

The SOM contains the largest terrestrial SOC pool globally, and it is a source of GHGs $\left(\mathrm{CO}_{2}\right.$, nitrous oxide $\left[\mathrm{N}_{2} \mathrm{O}\right]$, and methane $\left[\mathrm{CH}_{4}\right]$ ) and other gases as exposed to tillage and erosion under annual cropping systems that involve significant amounts of tillage (Reicosky et al. 1997; Al-Kaisi and Yin 2005). Tillage intensity and soil degradation are among the major causes for the acceleration of SOC stocks loss or pool loss (Young et al. 2014). The mechanisms involved in loss of SOC stocks or pool loss due to soil erosion as a result of intensive tillage can include SOM oxidation and degradation of SOC stock or pool (Guzman and Al-Kaisi 2010a; Lal 2003).

The size of SOC pool is approximately $2,300 \mathrm{Pg}\left(2.5 \times 10^{12} \mathrm{tn}\right)$ to $2 \mathrm{~m}(6.6 \mathrm{ft})$ soil depth, which is four times the biotic/ vegetation pool and three times the atmospheric C pool. In contrast, the terrestrial C pool of 2,860 Pg $\left(3.2 \times 10^{12} \mathrm{tn} ; 2,300\right.$ $\mathrm{Pg}$ in soil, $60 \mathrm{Pg}\left[6.6 \times 10^{10} \mathrm{tn}\right]$ in detritus material, and $560 \operatorname{Pg}\left[6.2 \times 10^{11} \mathrm{tn}\right]$ in live biomass) is $57 \%$ of the geological pool and four times the atmospheric C pool (Lal 2003). Changes in the soil environment can subsequently lead to chemical and biological reactions (Troeh et al. 2004). These processes include oxidation and mineralization of organic compounds during the physical and weathering processes leading to the release of by-products such as $\mathrm{CO}_{2}$, $\mathrm{N}_{2} \mathrm{O}$, and $\mathrm{CH}_{4}$ (Lal 2003).

Lal (2003) summarized the effect of erosion on soil C dynamics. The pathways for SOC loss is intertwined with agriculture management systems, where practices and tillage systems in particular are the driv- 
ing forces of SOC losses in row cropping systems (Olson et al. 2016). The depletion of SOC stock causes a decrease in productivity with the loss of SOM exceeding the $\mathrm{C}$ input in oxidative areas as compared to natural ecosystems (Guzman and Al-Kaisi 2010a). Loss of SOC with intensive tillage systems (an ecosystem disservice) may approach 20 to $50 \mathrm{Mg} \mathrm{ha}^{-1}$ (8.92 to $22.3 \mathrm{tn}$ $\mathrm{ac}^{-1}$ ) in 5 to 50 years following conversion from a natural ecosystem to conventional agriculture cropping systems (Davidson and Ackerman 1993; Lal 2004) depending on climate, soil type, drainage class, crop rotations, tillage systems, and residue management (Guzman and Al-Kaisi 2010b). The amount of oxidizable organic materials depends on the type of organic pool (active, passive, or recalcitrant).

\section{SOIL BIODIVERSITY DEGRADATION}

Biological diversity is an important component of soil ecosystem functions by providing essential services for nutrient cycling and productivity (table 1). Loss in biodiversity may include loss of habitats because of natural and human activities. The term biodiversity refers to the variety of all life on earth and explicitly recognizes how the interaction of different components of ecosystems results in the provision of essential services including social and recreational opportunities that are sources of inspiration and cultural identity (Hens and Boon 2003). Loss of biodiversity can be exacerbated by soil degradation. The subsequent reduction in soil biodiversity because of loss of SOC and nutrient pools leads to a downward cycling of reduced biomass production and declining sustainability of the soil resource to support biodiversity.

Soil biodiversity provides valuable services for agriculture production through nutrient cycling, where a symbiotic relationship between plant community and microorganisms is essential in maintaining functions (MEA 2005). The changes in soil physical, biological, and chemical properties can influence the dynamics of agroecosystems biodiversity in habitat for animals, plants, and macro- and microfauna and flora community. A shift in agroecosystem stability because of soil degradation can be a detriment to the functions of biodiversity and the ecosystems services delivered (table 1). One study examining the relationship between biodiversity and soil degradation and productivity found agrobiodiversity to be higher in soils having a rich fertility source (available $\mathrm{P}$ and total N) (Wood and Lenne 1999). In contrast, biodiversity was lower in degraded soils with low SOM on steep slopes.

The loss of soil biodiversity can have a devastating impact on its productivity. Shifts to a few high yielding crops and increased use of high inputs of fertilizers in an attempt to replace loss of SOC and nutrient pools can exacerbate the loss of biodiversity (Thrupp 2000; Mooney et al. 2005; MEA 2005). These changes in agricultural practices have been documented by several studies where land intensively cultivated is associated with medium to low agrobiodiversity due to the conversion of perennial ecosystems to annual crops and an increase in soil degradation (Hadgu et al. 2009; MEA 2005).

\section{SOIL PROPERTY CHANGE EFFECTS ON ECOSYSTEM SERVICES AND PRODUCTIVITY}

Soil properties, land use, and management practices have profound effects on ecosystem services. Soils formed in loess without root-restricting subsoils show slight yield reductions (5\%) with an increasing degree of erosion (Olson and Nizeyimana 1988). Higher corn yield reductions (24\%) have been found to occur when either loessderived soils with root-restricting subsoils (claypans or fragipans) or soils developed in glacial till were degraded. Successful management techniques often include modification of the biological, chemical, and physical properties of the degraded soils. Loss of SOC is the main driver for changing physical and biological properties and subsequently leads to degradation of soil functions that provide ecosystem services.

Sometimes, a slow rate of sediment deposition leads to soil formation and creation of fertile alluvial plains. However, when accelerated by anthropogenic activity, this deposition becomes a destructive erosion process with adverse on-site and off-site effects. Among on-site effects is a decline in soil quality on sloping land, a decrease in plant nutrient availability, reduced water use efficiencies, and a reduction in agronomic productivity (table 1) (Nizeyimana and Olson 1988). Decline in the root depth zone and reduction in available water capacity increases the susceptibility of degraded soils to pedological and agronomic drought.

Among soil physical properties that are negatively affected by soil degradation are soil's water holding capacity, which is most important to crop production (Andraski and Lowery 1992; Lowery et al. 1995; Bakker et al. 2007). A key uncertainty in projections of future drought is how soil responds to precipitation changes and potential evaporation increases. Andraski and Lowery (1992) noted that although the total amount of water stored (not necessarily readily plant available water) in the soil profile increased as degradation increased the clay content in the root zone, plant available water did not increase since plant roots could not extract the water from the clay. This has important implications for crop capacity to withstand intraseasonal drought and sustained interannual drought conditions.

In Europe, Bakker et al. (2007) noted that soil's available water use is the most important yield-determining factor. Bakker and colleagues reported that degradation, including soil erosion, is likely to significantly reduce productivity in southern countries in Europe. Bakker et al. (2007) concluded that, with adequate fertility and good management, the potential of a soil to produce corn was largely determined by the capacity of the soil to store and supply water to plants. Accordingly, many investigators have concluded or implied that the most important yield-limiting effects are the reduction in SOC stock, decreased rooting depth, and reduced plant available water.

\section{MANAGEMENT OF INTENSIFIED CROPPING SYSTEMS AND SOIL ORGANIC CARBON STOCKS}

Intensified cropping systems such as cornbased or corn-soybean based systems in the midwestern United States have a great deal of variation in crop rotations, tillage practices, uses (or not) of cover crops, drainage systems, and the customization of management to account for soil types and their characteristics, topography, man- 
agement skills, equipment, and resources. These variations in management under variable short- and long-term weather conditions affect the ecosystem services that SOC stocks are able to produce at field, watershed, and landscape levels. Some management practices can accelerate the release of $\mathrm{C}$ to the atmosphere $\left(\mathrm{CO}_{2}\right)$ and lead to a decline in the many ecosystem services that SOC stock provide. Swinton et al. (2007) introduced the concept of "disservices" where an adverse change in C stock, such as decrease in SOC, can lead to a loss in ecosystem services.

There are a number of processes, natural and anthropogenic, that lead to degradation of soil $\mathrm{C}$ stocks and disservices to the ecosystem. For example, raindrops can cause physical disintegration of soil aggregates and result in a decrease in soil porosity and water infiltration, an increase in soil erosion, and create soil compaction and crusts. Residue or vegetation on the soil surface provides some protection against this disintegration and loss. The basic strategy for restoring degraded soils is to create a positive SOC budget. How aboveground (vegetation) and belowground (roots) biomass is managed can also affect losses and gains of SOC stocks, and whether productivity is reduced or improved. Adoption of conservation agriculture systems and recommended management practices that retain and increase biomass can increase SOC stocks. Conversion of sloping and eroding soils to perennial land use (e.g., silvicultural, pastoral, agrosilivicultural, agropastoral, and agrosilvopastoral) also are strategies to improve ecosystem services by restoring SOC stocks, reducing soil erosion, improving soil quality, and increasing/sustaining agronomic productivity under changing and uncertain climate (Troeh et al. 2004).

Olson et al. (2013) conducted a longterm study in southern Illinois (United States) on sloping land similar to that being removed from production by the USDA Conservation Reserve Program (CRP). The experimental site area was in perennial grasses for the previous 15 years and used as a proxy for land in CRP that could be returned to agricultural production if the program was not extended or the landowner opted out. The CRP

\section{Figure 2}

No-tillage corn planted into cereal rye cover crops to reduce disturbance and erosion can increase soil organic carbon sequestration.

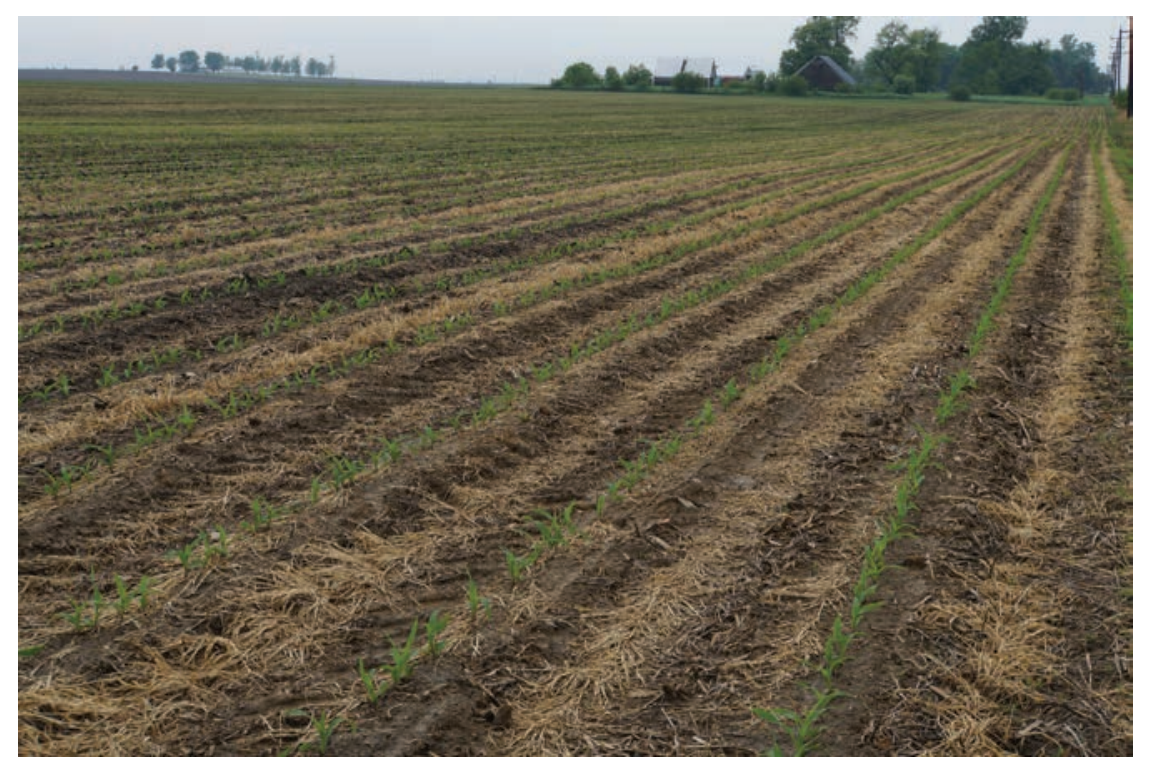

program was an early attempt to restore soil function and ecosystem services by addressing soil productivity, enhancing SOC stock, and reducing soil degradation. Soil data were gathered from 1988 to 2013 and analyzed to quantify the effects of tillage systems and accelerated erosion on the amount and rates of SOC loss, storage, retention, and sequestration. All tillage treatments (no-tillage [NT], chisel plow $[\mathrm{CP}]$, and moldboard plow $[\mathrm{MP}]$ ) lost SOC over time on sloping and eroding plot areas. Soil function was impaired after the perennial land was converted to corn-soybean based production.

Olson et al. (2014) introduced cover crops after 12 years of the existing tillage study in an attempt to retain existing SOC stocks and restore SOC stocks previously lost. The cover crops used were hairy vetch (Vicia villoso Roth) and cereal rye (Secale cereal L.). After soybean harvest, hairy vetch was seeded in the fall and was chemically burned the following spring just before planting corn. Cereal rye was seeded after corn harvest and chemically burned the following spring prior to soybean planting (figure 2). These cover crops helped retain SOC stocks on the plot area and contributed to the biomass (tops and roots) returned to the soil, with both contributing to increased net SOC stocks. After 12 years, the cover crops treatment had more SOC stocks than the plot without cover crops for the same layer and tillage treatment (Olson et al. 2014). The NT, CP, and MP treatments all sequestered SOC with cover crops. With the addition of cover crops, the tillage treatments (NT, CP, and $\mathrm{MP}$ ) gained SOC by $30 \%, 10 \%$, and $18 \%$, respectively. A pretreatment SOC stocks baseline for the rooting zone was used to validate the findings that cover crops sequestered SOC in the topsoil, subsoil, and root zone of all tillage treatments. Cover crops restored soil functions while providing valuable ecosystem services by reducing soil degradation.

This research demonstrates how management can affect the ecosystem services provided by soil, as indicated by the change in SOC stocks. In this experiment, a positive $\mathrm{C}$ budget in all tillage treatments up to about $75 \mathrm{~cm}$ (30 in) depth (root zone) resulted in SOC stock retention and storage. A positive $\mathrm{C}$ budget can rebuild the depleted/lost SOC stocks and restore soil functions.

\section{SUMMARY AND CONCLUSIONS}

Conceptually, soil degradation is the shifting of soil functionality from an optimal state to a less optimal state based on soil water holding capacity as a function of 


\section{Figure 3}

Tillage radishes and oat cover crop. Tillage radishes have large tap roots that break up shallow layers of compacted soils, increase soil water infiltration, retain soil moisture, and reduce soil erosion.



SOM. Loss of soil water holding capacity, a regulating ecosystem service, has large implications for crop management under increasing intraseasonal and interannual precipitation swings from drought to extreme rain events. One of the clearest trends in the US climate observational record is an increasing frequency and intensity of heavy precipitation in the Upper Midwest. Over the last century there has been a $50 \%$ increase in frequency of days with precipitation over $101.6 \mathrm{~mm}$ (4 in) in the Upper Midwest (Arritt 2016). Downscaled model forecasts for the future midwestern climate project the trend of increased heavy summer rainfall to continue and to strengthen into the next 30 years. When rainfall exceeds the infiltration rate of the soil and the soil has limited capacity to store water, there is an increase in runoff and sediment movement from agricultural landscapes and increased nutrient leaching through the soil. The combination of degraded soil, heavy precipitation, and poor management practices create a "perfect storm" for a downward spiral in soil functions and an increasing disservice to the ecosystem.

Agricultural management practices are critical factors in whether the soil resource and its ecosystem functions are lost or enhanced. The value farmers place on their soil and how they understand the soil-ecosystem functions in relation- ship to their management affect farm and landscape level productivity and will play an outsized role in the future of agriculture. Tillage practices and cover crops are part of a suite of practices that show promise of retaining and increasing SOC in cultivated systems (figures 2 and 3). An increase in biodiversity can have significant impact on SOC input through active below- and aboveground biomass production. This, in turn, can reduce the vulnerability of the ecosystem by increasing capacity to tolerate adverse effects of climate change and reduced water availability. Conversion of conventional plow-based tillage to NT or conservation tillage in conjunction with cover cropping can increase the SOC storage and increase $\mathrm{C}$ sequestration for rooting depth over a period of years. The continuous soil management goal is to restore SOC stocks and ensure soil functions and processes deliver valuable ecosystem services now and into the future.

\section{ACKNOWLEDGEMENT}

This research was funded by the USDA-National Institute of Food and Agriculture (NIFA), Award No. 2011-68002-30190, Cropping Systems Coordinated Agricultural Project: Climate Change, Mitigation, and Adaptation in Corn-based Cropping Systems.

\section{REFERENCES}

Adhikari, K., and A.E. Hartemink. 2016. Linking soils to ecosystem services-a global review. Geoderma 262:101-111.

Al-Kaisi, M.M., A. Douelle, and D. Kwaw-Mensah. 2014. Soil microaggregate and macroaggregate decay over time and soil carbon change as influences by different tillage systems. Journal of Soil and Water Conservation 69(6):574-580, doi:10.2489/jswc.69.6.574.

Al-Kaisi, M., and X.Yin. 2005. Tillage and crop residue effects on soil carbon and carbon dioxide emission in corn-soybean rotations. Journal of Environmental Quality 34:437-445.

Andraski, B.J., and B. Lowery. 1992. Erosion effects on soil water storage, plant water uptake and corn growth. Soil Science Society of America Journal 56:1911-1919.

Arritt, R. 2016. Climate Change in the Corn Belt. CSCAP-0193-2016. Ames, IA: Cropping Systems Coordinated Agricultural Project (CAP) Climate Change, Mitigation, and Adaptation in Corn-based Cropping Systems.
Bakker, M.M, G. Govers, R.A. Jones, and M.D.A. Rounsevell. 2007. The effect of soil erosion on Europe's crop yields. Ecosystems 10, 1209-1219.

Biggs, R., M. Schluter, D. Biggs, E.L. Bohensky, S. BurnSilver, G. Cundill, V. Dakos, T.M. Daw, L.S. Evans, K. Kotschy, A.M. Leitch, C. Meek, A. Quinlan, C. Raudsepp-Hearne, M.D. Robards, M.L. Schoon, L. Schultz, and P.C. West. 2012. Toward principles of enhancing the resilience of ecosystem services. Annual Review of Environment and Resources 37:421-48

Davidson, E.A., and I.L. Ackerman. 1993. Changes in soil carbon inventories following cultivation of previously untilled soils. Biogeochemistry 20:161-93

Dominati, E., M. Patterson, and M. Mackay. 2010. A framework for classifying and quantifying the natural capital and ecosystem services of soils. Ecological Economics 69(2010):1858-1868.

Guzman, G., and M. Al-Kaisi. 2010a. Soil carbon dynamics and carbon budget of newly reconstructed tall-grass prairies in South Central Iowa. Journal of Environmental Quality 39:136-146.

Guzman, G., and M. Al-Kaisi. 2010b. Landscape position and age of reconstructed prairies effect on soil organic carbon sequestration rate and aggregate associated carbon. Journal of Soil and Water Conservation 65(1):9-21, doi:10.2489/ jswc.65.1.9.

Hadgu, K.M., W.A. Rossing, L. Kooistra, and A.H. van Bruggen. 2009. Spatial variation in biodiversity, soil degradation and productivity in agricultural landscapes in the highlands of Tigray, northern Ethiopia. Food Security 1:83-97, doi:10.1007/ s12571-008-0008-5.

Hatfield, J., and L.W. Morton. 2013. Chapter 2 Marginality Principle. In Principles of Sustainable Soil Management in Agroecosystems, Advances in Soil Science, eds. R. Lal and B.A. Stewart, 19-55. New York, NY:Taylor and Francis, CRC Press.

Hatfield, J.L., and C.L.Walthall. 2015. Meeting global food needs: Realizing the potential via genetics $\mathrm{x}$ environment $\mathrm{x}$ management interactions. Agronomy Journal 107:4:1215-1226

Hens, L., and E.K. Boon. 2003. Causes of biodiversity loss: A human ecological analysis. Human Ecological Department,Vrije University Brussel, Laarbeeklaan 103, B-1090-Brussels.

Hussain, I., and K.R. Olson. 2000. Recovery rate of organic $\mathrm{C}$ in organic matter fractions of Grantsburg soils. Communications in Soil Science Plant Analysis 31:995-1001.

Lal, R. 2003. Soil erosion and the global carbon budget. Environmental International 29:437-450. 
Lal, R. 2015. Sustainable intensification for adaptation and mitigation of climate change and advancement of food security in Africa. In Sustainable Intensification to Advance Food Security and Enhance Climate Resilience in Africa, eds. R. Lal, B.R. Singh, D.L. Mwaseba, D. Kraybill, D.O. Hansen, and L.O. Eik. New York: Springer.

Lal, R., M. Griffin, J. Apt, L. Lave, and G. Morgan. 2004. Response to comments on 'Managing soil carbon.' Science 305(5690).

Lowery, B., J. Swan, T. Schumacher, and A. Jones. 1995. Physical properties of selected soils by erosion class. Journal of Soil Water Conservation 50(3):306-311.

MEA (Millennium Ecosystem Assessment). 2005. Ecosystems and Human Well-being: Biodiversity Synthesis. In Millennium Ecosystem Assessment (MEA). Washington, DC: World Resources Institute.

Mooney, H.A., A. Cooper, and W. Reid. 2005. Confronting the human dilemma. Science 434:561-562.

Nizeyimana, E., and K.R. Olson. 1988. Chemical, mineralogical and physical differences between moderately and severely eroded Illinois soils. Soil Science Society of America Journal 52:1740-1748.

Olson, K.R. 2013. Soil organic carbon sequestration in US cropland: Protocol development. Geoderma 195-196:201-206.

Olson, K.R., M.A. Al-Kaisi, R. Lal, and L. Cihacek. 2016. Impact of soil erosion on soil organic carbon stocks. Journal of Soil and Water Conservation 71(3):61A-67A, doi:10.2489/jswc.71.3.61A.

Olson, K.R. S.A. Ebelhar, and J.M. Lang. 2013. Effects of 24 years of conservation tillage system on soil organic carbon and soil productivity. Special issue: Soil Management for Sustainable Agriculture 2013. Applied Environmental Soil Science (1):1-10.
Olson, K.R., S.A. Ebelhar, and J.M. Lang. 2014 Long-term effects of cover crops on crop yields, soil organic carbon stocks and sequestration. Open Journal of Soil Science 4:284-292.

Olson, K.R.,A.N. Gennadiyev,A.P. Zhidkin, and M.V. Markelov. 2012. Impact of land use change, slope and erosion on soil organic carbon retention and storage USA. Soil Science 177(4):269-278.

Olson, K.R., and E. Nizeyimana. 1988. Effects of soil erosion on corn yields of seven Illinois soils. Journal of Production Agriculture 1:13-19.

Reicosky, D.C., W.A. Dugas, and H.A. Hobert. 1997. Tillage-induced soil carbon dioxide loss from different cropping systems. Soil Tillage Research 41:105-108.

Swinton, S.M., F. Lupi, G.P. Robertson, and S.K. Hamilton. 2007. Ecosystem services and agriculture: Cultivating agricultural ecosystems for diverse benefits. Ecological Economics 64:245-252.

Thrupp, L.A. 2000. Linking agricultural biodiversity and food security: The valuable role of agrobiodiversity for sustainable agriculture. International Affairs 76:265-281.

Troeh, F.R., J.A. Hobbs, and R.L. Donohue. 2004. Soil and water conservation: Productivity and environmental protection, 4th ed. Upper Saddle River, NJ: Prentice-Hall, Inc.

Wood, D., and J.M. Lenne. 1999. Why agrobiodiversity? In Agrobiodiversity. Characterization, utilization and management, eds. D. Wood and J.M. Lenne. Wallington: CABI.

Young, C.J., S. Liu, J.A. Schumacher,T.E. Schumacher, T.C. Kaspar, G.W. McCarty, D. Napton, and D.B. Jaynes. 2014. Evaluation of a model framework to estimate soil and soil organic carbon redistribution by water and tillage using ${ }^{137} \mathrm{Cs}$ in two US Midwest agricultural fields. Geoderma 232-234:437-448. 